\title{
DISCURSO E ETNOGRAFIA NA PESQUISA SOBRE LETRAMENTO NA COMUNIDADE
}

\author{
Guilherme Rios
}

\section{ABSTRACT:}

In this paper on literacy in the community, I argue for the gains of research in discourse, particularly Critical Discourse Analysis, in combination with an ethnographic approach. If for one hand Discourse Analysis proposes to be a tool to make clear the ideological investments in textual materiality (Fairclough, 1992), on the other hand such investment is partially raised in social practices and their networks, of which it is a part. From the relation of discourse with other aspects of social practice, such as participant's systems of values, beliefs and knowledge in the events, upsurges the need to incorporate an ethnographic approach, as much as a mode of knowledge production as a set of techniques implemented to generate data on those aspects of social practice.

KEY WORDS: Critical Discourse Analysis; ethnography; research methodology; literacy in the community.

\section{INTRODUÇ̃̃o}

A investigação sobre o uso e representações de leitura e escrita dentro e fora do contexto escolar tem trazido a necessidade de observar aspectos que extrapolam o processo meramente de produção textual, tais como as ações, as redes de relacionamento, valores e crenças dos participantes na interação em eventos e práticas sociais. Todos esses aspectos podem ser captados por meio de uma série de técnicas de pesquisa - questionários, entrevistas, diários dos participantes. No entanto, para uma construção de significados do lugar dos participantes nos eventos sociais é preciso mais que a aplicação de métodos, é preciso uma abordagem que tenha implicações na maneira de produzir o conhecimento no trabalho de pesquisa, ou mais precisamente, uma abordagem etnográfica. No bojo desta contribuição para o debate, está a distinção epistemologia/ 
metodologia instaurada com o crescimento da perspectiva etnográfica na "virada social" dos estudos lingüísticos. Tomando essa distinção como ponto de partida, exporei algumas conseqüências dessa visão para a pesquisa lingüística, particularmente uma combinação entre etnografia e análise do discurso, ilustrando com um ou outro caso do meu trabalho passado (Rios, 2003) ${ }^{1}$.

\section{Discurso e Etnografia}

Para iniciar a discussão sobre o liame entre métodos etnográficos e análise do discurso, vejamos o seguinte excerto:

G: Você usa o dicionário pra saber o significado de palavras?

Z: (...) porque o João faz faixas, então vira e mexe a gente pega uma palavra, tenhodúvida,então“não,vouprocurarprimeiro", porquedesdepequena, quando de primeiraa quarta série, eu liamuito gibi, entãoé uma das coisasque eu/ GraçasaDeus, umacoisaqueeunãotenhomuitoéerrodecaligrafia,p.ex.em escritasdepalavras, entãouma vezou outra vocêtátãocansado, quevocêfala assim “não,seráqueessapalavraécomissomesmo?seescrevecom'x',seescreve com 's'?", aí você sempre recorre pra procurar, mas significado não.

Nessa troca comunicativa numa das entrevistas de minha pesquisa de doutoramento, eu quero obter informações sobre os recursos utilizados pela participante em atividades de letramento, com a intenção de descobrir aspectos que levam a significados do contexto sociocultural. A participante nega usar o dicionário para obter o significado das palavras mas traz um exemplo sobre dúvida na ortografia das palavras. É digna de nota a mudança de voz na narrativa, instaurada com a interrupção marcada na seqüência pela

\footnotetext{
${ }^{1} \mathrm{O}$ estudo trata basicamente de uma descrição e análise dos usos, valores e aprendizagem da leitura e escrita em duas localidades socioeconomicamente diferenciadas no Distrito Federal: uma (quadra residencial 56) no Plano Piloto, a área central da cidade de Brasília, habitada por pessoas de classe média, e a outra (quadra residencial 34) no Paranoá, uma cidade na periferia de Brasília, habitada principalmente por pessoas de classe de baixa renda. Os nomes das quadras residenciais são pseudônimos utilizados para resguardar a identidade dos participantes da pesquisa.
} 
barra (/): “(...) então é uma das coisas que eu/ Graças a Deus, uma coisa que eu não tenho muito é erro de caligrafia (ortografia)". Ela tem consciência da exigibilidade da grafia de acordo com o padrão culto do português em eventos de letramento no domínio público e por isso consulta o dicionário para sanar dúvidas. Além disso, deixa a entender que na sociedade onde vive as pessoas são condenadas por cometerem "erros de ortografia", há uma questão moral na representação desse evento de letramento - não grafar as letras das palavras corretamente é vexatório, e em conseqüência, os indivíduos nessa situação têm sua imagem representada de modo negativo. Assim, examinando inicialmente o que seria um evento de letramento inocente - produção de faixas para fixação em espaço público - chegamos à consideração de significados como o pressuposto cultural da escrita correta das palavras no domínio público, a vergonha atribuída e consentida pelos escritores e a identidade social de escritor socialmente construída por meio da marcação das letras nas palavras.

A partir desse exemplo, qual a implicação entre as informações obtidas e os métodos para obtê-las?

Primeiramente, a descoberta de informações sobre valores, crenças, discursos dificilmente ocorre pela proposição de um questionário estruturado. São necessários o diálogo, as réplicas e tréplicas entre pesquisador e participante na negociação do que se supõe ser uma informação confiável. E o confiável na pesquisa qualitativa sempre decorre da qualidade da interação pesquisador-participante. $\mathrm{O}$ diálogo como um gênero central na interação pesquisador-participante é uma das principais características da etnografia. Uma outra característica é o materialismo.

Nas últimas décadas, a etnografia como uma metodologia de pesquisa tem se estendido a diversas áreas, tais como Educação e Lingüística, no momento em que essas áreas passaram a se envolver com estudos em outras culturas, os quais eram considerados dentro do escopo da Antropologia. Antes disso, porém, à luz de reflexões com base na descrição de culturas não-familiares, uma comparação com as culturas ocidentais foi inevitável; desse modo, desde a metade do século vinte vários antrópologos se voltaram para contextos familiares por meio do conceito de estranhamento (Marcus \& Fischer, 1986: 137). 
A etnografia introduziu nas ciências da linguagem uma dimensão epistemológica inescapável. Busca atores reais em eventos reais, utilizando códigos comunicativos reais com efeitos reais em mundos da vida reais. Uma abordagem etnográfica para a linguagem é uma abordagem que se inicia com fenômenos concretos, não-idealistas e não-apriori. O conhecimento construído na etnografia é conhecimento sobre a sociedade, em um sentido prático (Blommaert, 2001).

A etnografia constrói o conhecimento por meio do diálogo, em um sentido comum e prático mesmo. Etnografia é comunicação, isto é, comunicação ordinária entre dois sujeitos. Essa comunicação é um diálogo bakhtiniano e serve de explicação para a natureza interpretativa do conhecimento etnográfico.

Ambas as características situam a epistemologia etnográfica no reino dos procedimentos interpretativos do dia a dia. Daí a freqüência do status de 'inexplicável', intuitivo e autobiográfico de muito do que os etnógrafos 'sabem' sobre seus participantes. O método é freqüentemente acrescentado posteriormente, e a interpretação dos dados do campo é na prática a reconstrução de sentidos nos dados por meio de uma estruturação após o campo, também por meio de categorização e clarificação. O que essa reconstrução de sentidos nos dados tem de diferente em relação a uma simples aplicação de princípios interpretativos é que ela historiciza os dados, ou seja, o contexto mediador com suas significações no momento da coleta dos dados é parte integrante da interpretação dos dados.

A pesquisa etnográfica exige uma convivência mais ou menos extensiva com os participantes em seu meio. Exige também a atribuição de identidades para o pesquisador e para os participantes. Quem é o pesquisador para os participantes e quem são os participantes para o pesquisador? É montada através da produção de textos sobre o campo: impressões do pesquisador, descrições de cenas e interações e notas com reflexões sobre o que está acontecendo. Inclui relatos sobre o relacionamento entre pesquisador e pesquisado e foco nas experiências e práticas. Enfim, é uma maneira de ligar processos em nível micro a estruturas mais amplas (Hammersley \& Atkinson, 1995).

Uma questão bastante debatida na pesquisa social envolvendo a etnografia trata da possibilidade de combinar esta com a análise do discurso, e aqui nós particularmente nos remetemos à etnografia crítica e a análise de discurso 
crítica. A análise de discurso crítica tem advogado a necessidade de conhecer as condições de produção dos textos, especificamente uma visão processual dos textos. Isso implica movimentos analíticos que envolvem os eventos - as interações - e as práticas sociais até um nível complexo de redes de práticas. Venho mais especificamente realizando essa combinação teórico-metodológica com foco nos Novos Estudos do Letramento e na Análise de Discurso Crítica. Ambos figuram como campos científicos distintos, independentes entre si, e presentemente consolidados. Os Novos Estudos do Letramento têm sua fundação no diálogo entre a Antropologia, a Psicologia, a Educação e a Lingüística, enquanto a Análise de Discurso Crítica tem realizado suas fontes na Filosofia, na Sociologia e na Linguística (ver Pitt, 2001). Os métodos de pesquisa usuais nos Novos Estudos do Letramento são a etnografia e a análise de conteúdo, ao passo que para a Análise de Discurso Crítica tem sido a coleta de um corpus de textos relativamente extenso, em que se realizam as análises lingüísticas e textuais, acrescidas de abordagens interpretativas nas Ciências Sociais. No entanto, não é incompatível trazer uma abordagem etnográfica para a Análise de Discurso Crítica (ver, por exemplo, Chouliaraki, 1995 e também a sugestão em Blommaert \& Bulcaen, 2000), e Fairclough (1995) reconheceu que alguns trabalhos na Análise de Discurso Crítica, freqüentemente, até então, haviam falhado em historicizar os dados.

Um outro ponto importante na integração entre os Novos Estudos do Letramento e a Análise de Discurso Crítica reside precisamente no encontro entre a face epistemológica da etnografia e as noções de contexto e prática social em Análise de Discurso Crítica. A etnografia e a Análise de Discurso Crítica freqüentemente se coincidem na investigação do contexto, societal, institucional e situacional, embora a análise de texto e da interdiscursividade não tenham sido normalmente uma preocupação para a etnografia no passado. Ambos contexto e prática social envolvem o texto e a língua numa configuração tão amarrada, que não deveríamos perdê-la de vista. Abaixo ofereço uma alternativa para mapear essa configuração: 


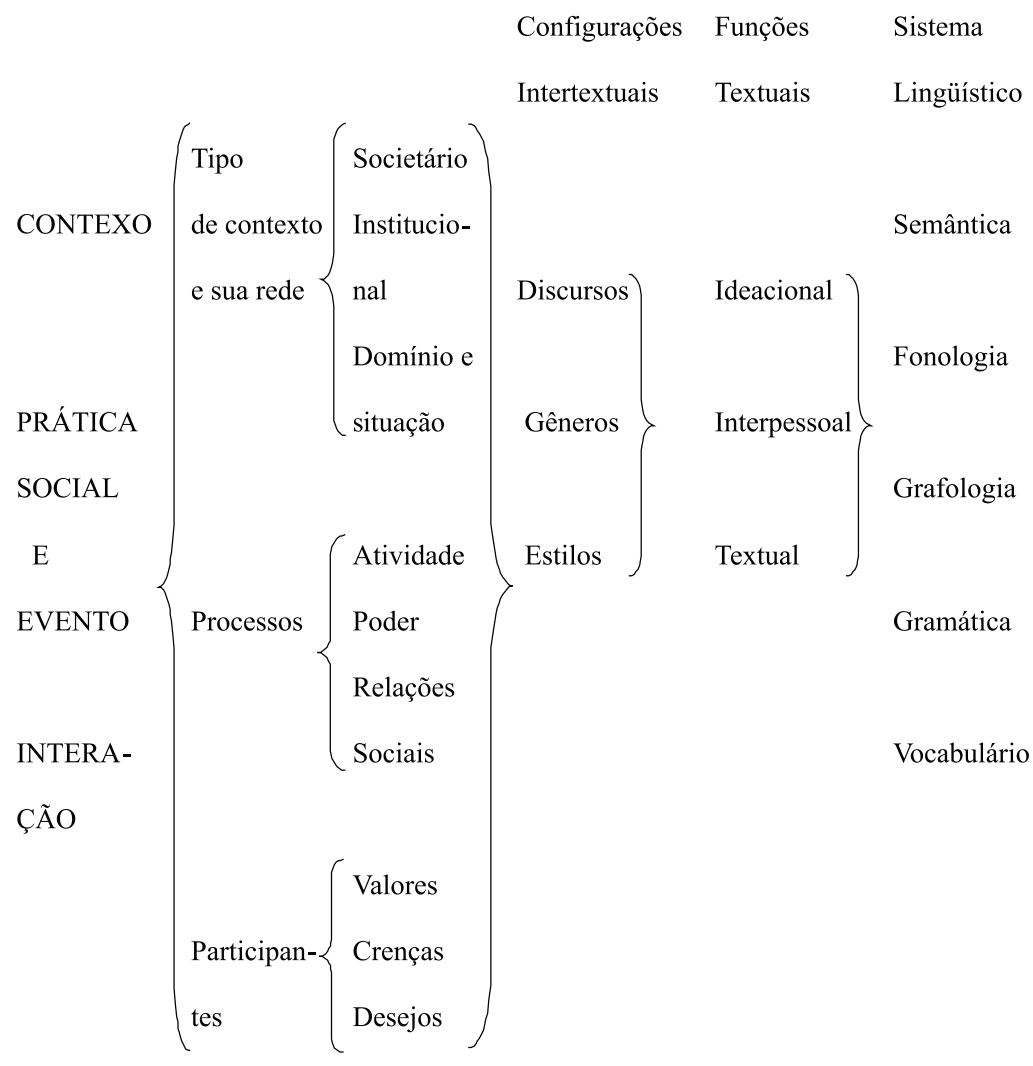

Figura 1. Etnografia e Análise do Discurso

Este gráfico é baseado em uma descrição ampla do contexto e da prática social na Antropologia, a qual tem suas origens em Malinowski (1922), na tradição de estudos etnográficos do letramento (Street, 1995; Barton \& Hamilton, 1998) e em construtos na Lingüística Sistêmico-Funcional (Halliday \& Hasan, 1985; Halliday, 1994) e na Análise de Discurso Crítica (Fairclough, 1992; Chouliaraki \& Fairclough, 1999). Enquanto as categorias sociais de tipo de contexto, processos e participantes são desdobradas nas subcategorias acima, as categorias de língua, texto e discurso desdobram-se em toda a extensão do que segue. A consideração aqui é que todo elemento lingüístico, textual e discursivo é um contribuinte, em maior ou menor grau, para as subcategorias e categorias no contexto e na prática 
social. Essa idéia se harmoniza com a noção dialética sobre a interação no interior dos recursos discursivos e entre o discurso e os outros momentos da prática social. ${ }^{2}$

2. Diálogo, autoridade de interpretação e Validade na entrevista ETNOGRÁFICA

A etnografia crítica adota uma posição de princípio segundo a qual os participantes deveriam ter suas vozes preservadas em relação às vozes dos outros afirmadas em posições de poder na pesquisa. Como uma consequiência, as narrativas de eventos são consideradas aqui dentro de uma lógica dialógica onde os assuntos das questões de pesquisa podem passar dissimulados, podem ser contraditados e esquecidos de acordo com as pistas de interpretação nas perguntas.

Esse diálogo, para ser validado como confiável, precisa da consciência crítica dos investigadores de sua posição social em enquadres histórico-ideológicos, consciência que regulará a linguagem de investigação - o discurso - de uma tal maneira que os participantes não sejam sutilmente compelidos a usar linguagem que se ajuste a esses enquadres histórico-ideológicos, reproduzindo posições de subordinação na interação. Isto é bastante difícil na prática, porque até mesmo quando nós tentamos monitorar a linguagem com o propósito de deixar os participantes falarem sem a influência de nossos pressupostos, a interpretação que eles/elas fazem das perguntas depende sobremaneira do momento psicológico da entrevista. Por exemplo, no extrato abaixo Carlos compreende a pergunta em termos de um conselho, como se fosse "Você já pensou em planejar suas atividades diárias?".

G: Cê planeja suas atividades diárias?

C:Não, nãoplanejo, rapaz, éeu acho que até éuma falha/às vezes sai tudo errado,ontemmesmo(inint), porfaltadeplanejamento, denãoteridolá, eu já pensei nisso, mas eu não planejo não.

\footnotetext{
${ }^{2} \mathrm{Na}$ versão mais atual da relação entre discurso e prática social (Chouliaraki \& Fairclough, 1999), tem-se o conceito de prática social como centro aglutinador constituído de "momentos", tais como o discurso, as atividades materiais, as relações sociais e institucionais de poder e os fenômenos mentais (crenças, desejos, valores). Esses momentos relacionam-se dialeticamente entre si, interiorizando os outros e por eles sendo interiorizados.
} 
Ele faz assim justapondo uma oração avaliativa: "eu acho que até é uma falha”, e apresentando um argumento: “às vezes ... de não ter ido lá”, logo após dando uma resposta direta à pergunta. Esse complemento para a resposta era inesperado, e sua combinação com a oração final "eu já pensei nisso, mas eu não planejo não" mostra como ele interpreta a intenção na pergunta. Porém, isso não dizer que renunciaríamos a minimizar a semiose de poder que podemos exibir em entrevistas. Essa questão deve ser levada em conta no momento da análise, de tal maneira que as respostas devam ser examinadas junto com as perguntas.

Quando passamos depois para a análise, as vozes dos participantes tendem a ecoar como expressões da verdade sobre a experiência deles/delas em relação a um tópico. Concebo verdade como uma aproximação do que está sendo contado, de forma que eu não reivindico que os participantes estejam contando as coisas exatamente como aconteceram, mas como reconstruções que são significativas na visão de mundo presente deles/delas, e assim, com algumas distorções governadas por valores do presente (Lummis, 1998: 276). Assim, é importante analisar a estrutura da entrevista e fazer referências cruzadas para entender os valores do presente dos participantes (ibidem), e examinar até que ponto eles influenciam as respostas.

Há uma conhecida controvérsia a respeito da validade das entrevistas como instrumento para captar a veracidade das informações fornecidas pelos participantes (ver Hammersley, 2005). Freqüentemente, os argumentos contrários ao uso de entrevistas são dirigidos por analistas do discurso aos etnógrafos. Este ponto acrescenta-se a um falso dilema segundo o qual haveria uma incompatibilidade intransponível entre a análise do discurso e a etnografia, se atentarmos para o que diz Hammersley (2005: 14):

(...) a análise do discurso não estaria em competição com a etnografia, mas seria simplesmente um diferente empreendimento com um foco diferente; e de fato um que poderia gerar recursos que poderiam ser de uso valioso para os etnógrafos. Em contraste, ao adotar uma visão cética como um compromisso epistemológico implica rejeitar não apenas a etnografia mas também a análise do discurso, em favor da produção de textos auto-subversivos que continuamente comprometem qualquer reivindicação de conhecimento que eles façam. 
Conforme Hammersley, há quatro tipos de argumentos postos em contra ao uso de entrevistas. Pelo primeiro, nenhum dado que não seja coletado de processos naturalmente ocorrentes é válido. Assim, as intervenções realizadas por pesquisadores/as por meio de entrevistas estruturadas ou semi-estruturadas eliminam o caráter natural da coleta de dados. Tal argumento está associado ao 'paradoxo do observador', apontado por Labov (1972), segundo o qual ao mesmo tempo em que o/a pesquisador/a obtém dados empíricos da realidade observada ele/a exerce efeitos sobre essa mesma realidade. Porém, esta é uma posição problemática, pois há o pressuposto da pesquisa positivista, onde o/a observador/a deve manter um distanciamento e evitar qualquer tipo de influência sua sobre o objeto estudado.

O segundo argumento é o da falibilidade do registro dos dados tanto por observação como por aparelhos gravadores e posterior transcrição. A questão colocada é que em geral não haveria rigor científico na coleta de relatos de participantes de pesquisa, reconhecidamente na etnografia, e portanto os relatos seriam seletivos, inferenciais e sujeitos à distorção pela memória, carentes assim de verificação pelos/as pesquisadores/as.

O terceiro argumento afirma a impraticabilidade de obter informações sobre as experiências particulares das pessoas. Não haveria como dizer se as representações de fenômenos mentais ou de conhecimento privado das pessoas são mais ou menos acuradas, elas são na verdade amostras discursivas pelas quais as ações, os contextos e as subjetividades são correntemente constituídos. O que há para observar são as formas narrativas e as estratégias retóricas empregadas pelos participantes ao narrarem suas experiências.

Por fim, o último argumento refere-se ao ceticismo com base na idéia de que os relatos podem sequer representar a realidade, seja "externa" ou "interna". Esse é um princípio que tem guiado alguns tipos de etnografia, no sentido de que as perspectivas dos participantes dependem dos pressupostos distintivos da cultura, servindo a várias funções mais do que simplesmente refletir a natureza do mundo (Hammersley, 2005:12).

$\mathrm{O}$ autor rebate um a um desses argumentos. Contra o primeiro, o naturalismo, aponta que há outras maneiras para o tratamento das reações dos participantes, as quais não se atêm somente à minimização da influência do observador; é preciso também examinar os efeitos dessa influência e adotar 
uma posição reflexiva. Quanto ao segundo, substituir notas de campo por transcrições de áudio é enganoso pois estas também são resultado de um trabalho seletivo e inferencial pelo pesquisador. Além disso, a discussão levantada acima por Lummis (1998) pode esclarecer esse ponto, uma vez que pode importar menos a proximidade com o real no tempo da experiência do que os valores presentes mantidos sobre esta pelos/as participantes. Em relação ao terceiro, embora os relatos das experiências dos/as participantes façam referência a recursos coletivos por serem formulados na linguagem, não se pode negar a unicidade das experiências pessoais ou que as pessoas tenham diferentes fontes de informação as quais não são passíveis de acesso a outras pessoas. Por fim, o ceticismo quanto à possibilidade de representação de uma realidade única, perfeitamente compartilhada entre os sujeitos, favorece a investigação de um outro objeto - as estratégias retóricas ou estruturas narrativas utilizadas nos relatos dos participantes para a representação da realidade.

\section{Alguns EXEMPLOS}

Nesta seção tratarei sobre como me conduzi na prática frente às questões teóricas discutidas acima. Em primeiro lugar, abordei as pessoas apresentando-me como um pesquisador universitário e explicando sobre a pesquisa. Mais adiante, assegurei aos participantes que a confidencialidade seria preservada, por meio de uma breve introdução escrita no questionário. Então eu lhes perguntei se gostariam de participar em uma entrevista sobre os seus usos de leitura e escrita. Segui um conjunto de temas para as entrevistas - que foram adaptados do Projeto de Letramento na Comunidade $^{3}$ - para auxiliar como um guia. As entrevistas começaram com uma explicação oral feita por mim sobre os objetivos da pesquisa e então passei um formulário de consentimento para os participantes assinarem. Eu os instruí a responder o que eles fizeram de fato, a não se preocuparem com

\footnotetext{
${ }^{3} \mathrm{O}$ projeto de pesquisa Letramento na Comunidade foi desenvolvido por David Barton na cidade de Lancaster, no Reino Unido, com apoio da agência de fomento britânica ESRC, na década de 1990, tendo por foco os usos socioculturais de letramento e seus respectivos valores, redes, papéis em uma comunidade de classe média. A pesquisa foi relatada em Barton \& Hamilton (1998).
} 
minhas expectativas, e a estarem livres para não responder nada do que eles não quisessem. Normalmente fiz perguntas em aberto e só em casos onde os/as participantes deram uma resposta completamente fora do tópico ou mostraram desentendimento eu repeti ou insisti em um tipo particular de resposta. Se nas respostas os/as participantes tocavam em um momento crucial nas vidas deles/delas eu punha o guia de entrevista de lado e deixava o entrevistado falar livremente. Estes modos de entrevistar foram inspirados no que é conhecido como entrevista não-estruturada, criativa e pós-moderna (Frey \& Fontana, 1998; vide também McKracken, 1988). Esse tipo de entrevista assegura a integridade das vozes dos/as participantes de pesquisa, sem assimilá-las à do investigador. Todos esses procedimentos foram estratégias de que eu me vali para assegurar validade e confiabilidade. Outras estratégias foram repetir um tema em outras partes da entrevista com uma formulação diferente para comparar, e uma segunda entrevista.

Passo agora a discutir os modos pelos quais formas particulares de agir e representar a pesquisa por mim e pelos participantes amoldaram as identidades iniciais de pesquisador e participantes, bem como construíram identidades novas para os atores envolvidos na pesquisa.

Os modos como os participantes entenderam a pesquisa acarretou a negociação de papéis que foram enfim assumidos durante o processo de pesquisa. Esses papéis contribuíram para o amoldamento das maneiras como as entrevistas foram realizadas, como também para o levantamento de temas particulares. Especificamente no Paranoá, meu papel era compreendido por alguns participantes, notavelmente Eva, como um professor. Também tive minha identidade construída pela interação em duas entrevistas como um assistente social. E em um certo sentido, foi levantado o papel de orientador psicólogo. No Plano Piloto, ao papel de professor acrescentou-se o de biógrafo. Especificamente na associação de residentes da quadra 56 desempenhei o papel de consultor, ao auxiliar Hilda (a secretária) na escritura de cartas a órgãos oficiais e de circulação interna à quadra.

A identidade de professor me ajudou a ganhar a confiança dos/as participantes e direcionou os temas para a escola e a educação. A identidade de assistente social surgiu em duas situações. Primeiramente, depois da entrevista com Eva, quando ela sugeriu que eu lhe pudesse oferecer um emprego. Em seguida, 
depois da entrevista com Luisa, quando ela me falou sobre suas dificuldades em encontrar um emprego estável. Ela não sugestionou o que eu poderia fazer para ajudá-la, como Eva fez, mas senti-me um pouco no dever de lhe ajudar nesse sentido. A identidade de biógrafo foi ativada pelo foco das perguntas nas vidas dos participantes. Por exemplo, Fernando e Luisa começaram a refletir sobre o que as perguntas de entrevista estavam significando para suas próprias vidas. Nesse sentido, ambas as identidades de assistente social e biógrafo pareceram ter contribuído também para fazer da entrevista algo de interesse para os participantes. Fernando disse que a entrevista estava lhe ajudando a se lembrar de fatos na história de sua vida, como também exercitando sua memória. Luisa mencionou como a entrevista a estava fazendo ver as mudanças em relação aos usos de leitura e escrita que aconteceram em sua vida.

As identidades de pesquisador e pesquisado estão em função dos gêneros encontrados na entrevista etnográfica. Como um aspecto importante, a totalidade das entrevistas de pesquisa configura uma hibridização de gêneros de tal maneira que podemos encontrar partes de narrativas, conversação, fala expositiva, argumentação, biografia e aconselhamento psicológico. Em conformidade com um critério de hierarquia, a narrativa e a conversação são gêneros primários nos textos das transcrições de entrevistas, uma vez que são os mais freqüentes, enquanto os outros figuram como gêneros secundários. O aconselhamento psicológico foi particularmente significativo quando os/ as participantes interpretaram uma questão como se estivesse realizando uma sugestão para agir de modo a superar um problema.

A conversação também é desejável na entrevista qualitativa não-estruturada ou pós-moderna. Um dos aspectos principais desse gênero é a equalização da iniciação do tópico e da tomada do turno entre pesquisador/a e participante. Embora as entrevistas de pesquisa tratem habitualmente de interações assimétricas onde o pesquisador inicia e controla o tópico e o turno, houve duas situações nas entrevistas conduzidas por mim em que essa organização foi rompida. Na primeira, às vezes encontrei-me na posição de ser questionado, e na segunda os/as participantes responderam livremente as questões da maneira que melhor se lhes ajustassem. Veja, por exemplo, o excerto abaixo, em que a participante se estende com informações pessoais sobre sua relação com a leitura e a escrita no domínio da religião: 
E: Ih no púlpito ele prega, ele é um amor de pessoa, ele é muito conhecido o pastor Adalberto.

G: Bom agora/

E: [Bulhon, conhece o Bulhon?

G: Acho que já ouvi falar.

E: Pastor de todas as igrejas, ele é da minha e igreja, ele é pastor é: era da minha igreja, eu era da igreja dele no caso (inint) é o Bulhon é pastor de todos os pastores, que ele é quem comanda todos os pastores, ele é acima de todos, inclusive você já assistiu, professor, aquele programa Está Escrito?

G: Não/

E: É da Igreja Adventista do Sétimo Dia ta no ar eu não sei se é na TV Bandeirantes é na parte da manhã 6, 7 meia não sei qual é o horário Está Escrito é um programa muito vivo de sabedoria e ele é dele, o Bulhon.

\section{CONCLUSÃo}

A pesquisa etnográfica baseia-se no diálogo entre pesquisador/a e participantes e na materialidade cultural - a existência real de atores e eventos, questões, códigos e efeitos reais em mundos da vida. As formas mais recorrentes desse diálogo são as entrevistas. As questões postas sobre a validade das entrevistas na pesquisa etnográfica devem antes figurar como ameaças que poderiam comprometer o grau de aproximação da realidade da questão investigada, por pesquisadores/as e participantes, para que potenciais distorções possam ser minimizadas, em vez de um impedimento irreversível ao alcance dos sentidos no interior do diálogo inerente à etnografia.

A pesquisa etnográfica gera textos autorados por ambos pesquisador/a e participante, os quais são analisados numa perspectiva de discurso, de sentidos construídos de um lugar social. Os significados socioculturais são revelados por meio da análise do discurso e das práticas socioculturais. O que é mais importante é não conceber o processo de pesquisa de uma forma naturalizada, mas compreender que esse processo é construído na reflexão que seus atores 
realizam a cada passo, a cada etapa, nas coincidências e nos equívocos gerados na comunicação entre pesquisador e participante. Nesse aspecto, as identidades assumidas no processo de pesquisa são relevantes para a construção da relação pesquisador/a-participante e, conseqüentemente, para garantir sua validade. Em um contexto onde há nítidas posições de poder diferencialmente distribuídas entre pesquisador/a e participante, construídas em relações de gênero, raça, ou etnia, para citar algumas categorias, a capacidade para a geração de dados de natureza etnográfica válidos e confiáveis dependerá em grande parte da reflexão e das ações decorrentes desta pelo/a pesquisador/a com a intenção de promover um diálogo autêntico com as participantes.

REFERÊNCIAS BIBLIOGRÁFICAS:

BARTON, D. \& M. HAMILTON. Local literacies. London: Routledge, 1998. BLOMMAERT, J. Comments and reflections. Linguistic Ethnography in the UK. BAAL/CUP Seminar. University of Leicester, 2001.

BLOMMAERT, J. \& C. BULCAEN. Critical Discourse Analysis. Annua Review of Anthropology 29: 447-466, 2000.

CHOULIARAKI, L. Regulative practices and heteroglossia in one institutional setting: the case off a 'progressivist' English classroom. Unpublished Ph.D. thesis. Linguistics Department, University of Lancaster, 1995.

CHOULIARAKI,L.\&N.FAIRCLOUGH. Discoursein latemodernity.Edinburgh: Edinburgh University Press, 1999.

FAIRCLOUGH, N. Discourse and social change. Cambridge: Polity Press, 1992. FAIRCLOUGH, N. Critical Discourse Analysis. London: Longman, 1995.

FREY, J. \& A. FONTANA. Interviewing: the art of science. In: N.Denzin \& Y.Lincoln,(orgs.)Collecting andinterpreting qualitativematerials. Thousand Oaks, California: Sage, 1998, pp. 47-78.

HALLIDAY, M.A.K. Introduction to functional grammar, 2ed. London: Edward Arnold, 1994.

HALLIDAY, M.A.K. \& R. HASAN. Language, context and text: aspects of language in a social semiotic perspective. Oxford: Oxford University Press, 1985.

HAMMERSLEY, M. \& P. ATKINSON. Ethnography: principles in practice. London: Routledge, 1995. 
HAMMERSLEY, M. Ethnography and discourse analysis: incompatible or complementary?. Polifonia, 10: 1-20, 2005.

LABOV, W. Sociolinguistic patterns. Philadelphia: University of Pennsylvania Press, 1972.

LUMMIS, T. Structure and validity in oral evidence. In: R. Perks and A. Thomson (orgs.) The oral history reader. London: Routledge, 1998, pp. 273-283.

McKRACKEN, D. The long interview. London, Thousand Oaks, California: Sage, 1988.

MALINOWSKI, B. Argonauts of the Western Pacific. London: Routledge, 1922.

MARCUS, G. \& M. FISCHER. Anthropology as cultural critique. Chicago and London: University of Chicago Press, 1986.

PITT, K. The discourse of family literacy. Unpublished Ph.D. thesis, Linguistics Department, Lancaster University, 2001.

RIOS, G. Literacy discourses in two socioeconomically differentiated neighbourhoods in Brazil. Unpublished Ph.D. thesis. Lancaster: Linguistics Department, Lancaster University, 2003.

STREET, B. Social literacies: critical approaches to literacy in development, ethnography and education. London: Longman, 1995. 